\title{
Study by DTA/TG of the formation of calcium aluminate obtained from an aluminium hazardous waste
}

\author{
A. López-Delgado • F. A. López • L. Gonzalo-Delgado • \\ S. López-Andrés $\cdot$ F. J. Alguacil
}

\begin{abstract}
A Spanish hazardous waste from tertiary aluminium industry was used as a raw material for the synthesis of calcium aluminate. An amorphous precursor was obtained by a hydrothermal method at different values of $\mathrm{pH}$. The transformation of the precursor in a crystalline aluminate was followed by TG/DTA up to $1300{ }^{\circ} \mathrm{C}$. At temperatures between 719 and $744{ }^{\circ} \mathrm{C}$, the precursors evolve towards the formation of $\mathrm{C}_{12} \mathrm{~A}_{7}$ which becomes $\mathrm{CA}$ at circa $1016{ }^{\circ} \mathrm{C}$. Mass spectrometry coupled to thermal analyser allowed the identification of the decomposition products.
\end{abstract}

Keywords Aluminium waste $\cdot$ Calcium aluminate TG/DTA

\section{Introduction}

Calcium aluminate compounds, $\mathrm{CaAl}_{2} \mathrm{O}_{4}(\mathrm{CA}), \mathrm{CaAl}_{4} \mathrm{O}_{7}$ $\left(\mathrm{CA}_{2}\right)$ and $\mathrm{Ca}_{12} \mathrm{Al}_{14} \mathrm{O}_{33} \quad\left(\mathrm{C}_{12} \mathrm{~A}_{7}\right)$ are widely used as hydraulic binders in the cement industry. $\mathrm{CA}$ is the main component of calcium aluminate cements and also plays an important role in the processing and manufacturing of macrodefect-free ceramic cements $[1,2]$. CA is also used as a refractory material in the steel industry.

A. López-Delgado $(\bowtie)$ · F. A. López · L. Gonzalo-Delgado ·

F. J. Alguacil

National Centre for Metallurgical Research, CSIC, Avda.

Gregorio del Amo, 8, 28040 Madrid, Spain

e-mail: alopezdelgado@cenim.csic.es

S. López-Andrés

Department of Crystallography and Mineralogy, Faculty

of Geology, University Complutense of Madrid, Madrid, Spain
Traditionally pure calcium aluminate phases are synthesized using solid-sate reactions. These reactions involve the sintering of mixtures of oxides or carbonates at high temperature and long time. Recently sol-gel methods and self-combustion or polymeric precursor methods are used as an alternative way to prepare homogeneous precursor phases [3-5]. In these methods, pure reactants (salts, oxides) are employed as starting materials.

In this article, the synthesis and the characterization of an amorphous calcium aluminate precursor obtained by hydrothermal treatment, at different values of $\mathrm{pH}$, from an aluminium hazardous waste (AHW), was studied. The formation of CA from the amorphous precursor was followed by Differential Thermal Analysis, DTA, Thermogravimetric Analysis, TG, and Mass Spectrometry, MS.

The AHW, a very fine powdery solid, generated by the tertiary industry of aluminium, is a complex material which consists of $\mathrm{Al}_{\text {metal }}$, corundum, spinel, aluminium nitride, quartz, calcite, iron oxide, other metal oxides, chlorides and other salts [6]. Slag produced in the secondary industry is profitable for the tertiary industry by means of milling, shredding and granulometric classification processes yielding different fractions which are commercialized according to the aluminium content. The finest fraction constitutes the "AHW" referred to above which is stored in safety containers. The European directive on waste, 2008/ 98/EC [7] defines the waste as H12 because of in the presence of water or humidity, AHW generates toxic gases as hydrogen, ammonia, methane and hydrogen sulphide.

Processes described for the treatment of AHW-relatedmaterials aimed, generally, to render inert products [8-10]. Recently, several procedures have been developed to recover the aluminium content as valuable products, and so the production of glasses [11], glass-ceramics [12] and boehmite [6] are reported. 
The aim of this work is to study by means of TG/DTA, the formation of monocalcium aluminate, CA, using a hazardous waste as Al-bearing product and $\mathrm{CaO}$. A low temperature hydrothermal method was employed to obtain the precursor phase.

\section{Experimental}

\section{Materials}

A sample of AHW, supplied by a tertiary aluminium industry (Recuperaciones y Reciclajes Roman S.L. Fuenlabrada, Madrid, Spain) was used as source material for $\mathrm{Al}_{2} \mathrm{O}_{3}$. The major mineralogical composition of the AHW is as follows: $31.2 \% \mathrm{Al}_{\text {metal }}, 20.0 \% \mathrm{Al}_{2} \mathrm{O}_{3}$ (corundum), $15.0 \% \mathrm{MgAl}_{2} \mathrm{O}_{4}$ (spinel), 8.4\% $\mathrm{AlN}, 8.0 \% \mathrm{SiO}_{2}$ (quartz), $8.2 \% \mathrm{CaCO}_{3}$ (calcite), $1.8 \% \mathrm{Fe}_{2} \mathrm{O}_{3}$ (haematite), $1.5 \% \mathrm{TiO}_{2}$, $1.5 \%$ chloride $(\mathrm{Na} / \mathrm{K}), 0.7 \% \mathrm{Al}_{2} \mathrm{~S}_{3}$ and other minor compounds (metal oxides). Pure $\mathrm{CaO}$ (Panreac 97\%), 10\% v/v $\mathrm{HCl}$ solution and 1-M NaOH solution were also used.

\section{Synthesis of precursor}

Aluminate precursors were synthesized by a hydrothermal process which consisted of the following stages: In the first one, a $10 \% \mathrm{v} / \mathrm{v} \mathrm{HCl}$ solution was used to dissolve the acidsoluble compounds of aluminium content in the AHW, fundamentally metallic aluminium and aluminium nitride. A suspension was obtained which was centrifuged and the $\mathrm{Al}^{3+}$ solution was separated of the insoluble solid. This acidic $\mathrm{Al}^{3+}$ solution was subjected to the second stage. In this one, a 1-M NaOH solution was added dropwise to a magnetically stirred $\mathrm{Al}^{3+}$ solution up to values of $\mathrm{pH}$ of 7 , 8 and 10 were reached. A gel started to precipitate from the first drop and when the corresponding $\mathrm{pH}$ value was achieved, $\mathrm{CaO}$, in the stoichiometric rate $\mathrm{Al} / \mathrm{Ca}$ to form the monocalcium aluminate was added. The suspension was aged with continuous stirring for $24 \mathrm{~h}$. Then the solid was separated by centrifugation and washed with deionized water until total chloride removing. The solid was dried at $60{ }^{\circ} \mathrm{C}$ during 4 days and then it was crushed in a mortar to get a fine powder and it was heated at $90{ }^{\circ} \mathrm{C}$ for $24 \mathrm{~h}$. The solid products obtained-aluminate precursors-were characterized by XRD and SEM. Then, they were subjected to thermal treatment to obtain the calcium aluminate and TG/DTA analysis was performed to study their evolution to calcium aluminate.

\section{Analysis and characterization}

The samples were chemically analysed by Atomic Absorption Spectroscopy (AAS, Varian Spectra model AA-220FS) and micro X-ray Fluorescence Spectroscopy (XRF, Bruker S8 Tiger model with $\mathrm{W}$ tube, $\mathrm{LiF}$ crystal analyser and $4 \mathrm{~kW}$ of voltage) for $\mathrm{Ca}$ - and $\mathrm{Al}$-specific content. $\mathrm{C}$ was determined by oxygen combustion in an induction furnace (Leco model CS-244). The identification of phases by X-ray diffraction (XRD) was performed by Bruker D8 Advance diffractometer at $2 \theta$ interval between $2^{\circ}$ and $70^{\circ}$, with $\mathrm{Cu}_{\mathrm{K} \alpha}$ radiation $(\lambda=1.5405 \AA)$. The morphological characterization of samples was performed by scanning electron microscopy (SEM, Field emission Jeol JSM 6500F). For observation, a powdered sample was embedded into a polymeric resin. A coating of graphite was used to get conducted sample. The Brunauer-Emmett-Teller (BET) surface area of the samples was obtained from nitrogenadsorption isotherms obtained in a Coulter SA 3100 system, at relative pressure range of 0.04-0.20. Samples were degassed for $4 \mathrm{~h}$ before measurement at $300{ }^{\circ} \mathrm{C}$.

The thermal analysis was performed by simultaneous TG/DTA (SETARAM DTA-TG Setsys Evolution 500), at a heating rate of $20{ }^{\circ} \mathrm{C} \mathrm{min}{ }^{-1}$, in $\mathrm{He}$ atmosphere up to $1300{ }^{\circ} \mathrm{C}$. Alumina crucibles with $30 \mathrm{mg}$ of sample were used. The outlet of the TGA was connected, through a capillary tube held at $200{ }^{\circ} \mathrm{C}$, to the mass spectrometer. In such a configuration, evolved gas products by the thermal treatment could be simultaneously analysed by quadrupolar mass spectroscopy (QMS).The ion detection was performed through secondary electron multiplier which detects very low pressures within Chaneneltron detector. A mass range between 40 and 130 atomic mass unit was studied.

\section{Results and discussion}

\section{Precursor characterization}

The $\mathrm{Ca} / \mathrm{Al}$ ratio of the precursors obtained at $\mathrm{pH} 7,8$ and 10 are: $0.654,0.757$ and 0.896 , respectively. The $\mathrm{Ca} / \mathrm{Al}$ ratio increases with the $\mathrm{pH}$ value. The theoretical $\mathrm{Ca} / \mathrm{Al}$ ratio for the stoichiometric $\mathrm{CA}$ is 0.743 . The $\mathrm{Ca} / \mathrm{Al}$ ratio for precursor obtained at $\mathrm{pH} 8$ is most nearly at the theoretical $\mathrm{Ca} / \mathrm{Al}$ ratio.

Figure 1 shows the XRD patterns of the precursors obtained at different $\mathrm{pH}$ values. The pattern of precursor obtained at $\mathrm{pH} 7$ can be assigned to $3 \mathrm{CaO} \cdot \mathrm{Al}_{2} \mathrm{O}_{3} \cdot \mathrm{CaCl}_{2}$. $10 \mathrm{H}_{2} \mathrm{O}$ (JCPDS 35-0105) which is a hydrated calcium aluminate with partial substitution of oxygen by chloride. The presence of this phase reveals the formation of reactive aluminate phases in the early stage of precursor formation, when $\mathrm{CaO}$ is added to the oxy-hydroxide aluminium gel [13]. The same phase is observed as the unique crystalline phase for precursor at $\mathrm{pH} 10$. However, the XRD pattern of precursor obtained at $\mathrm{pH} 8$ showed two phases: the above 


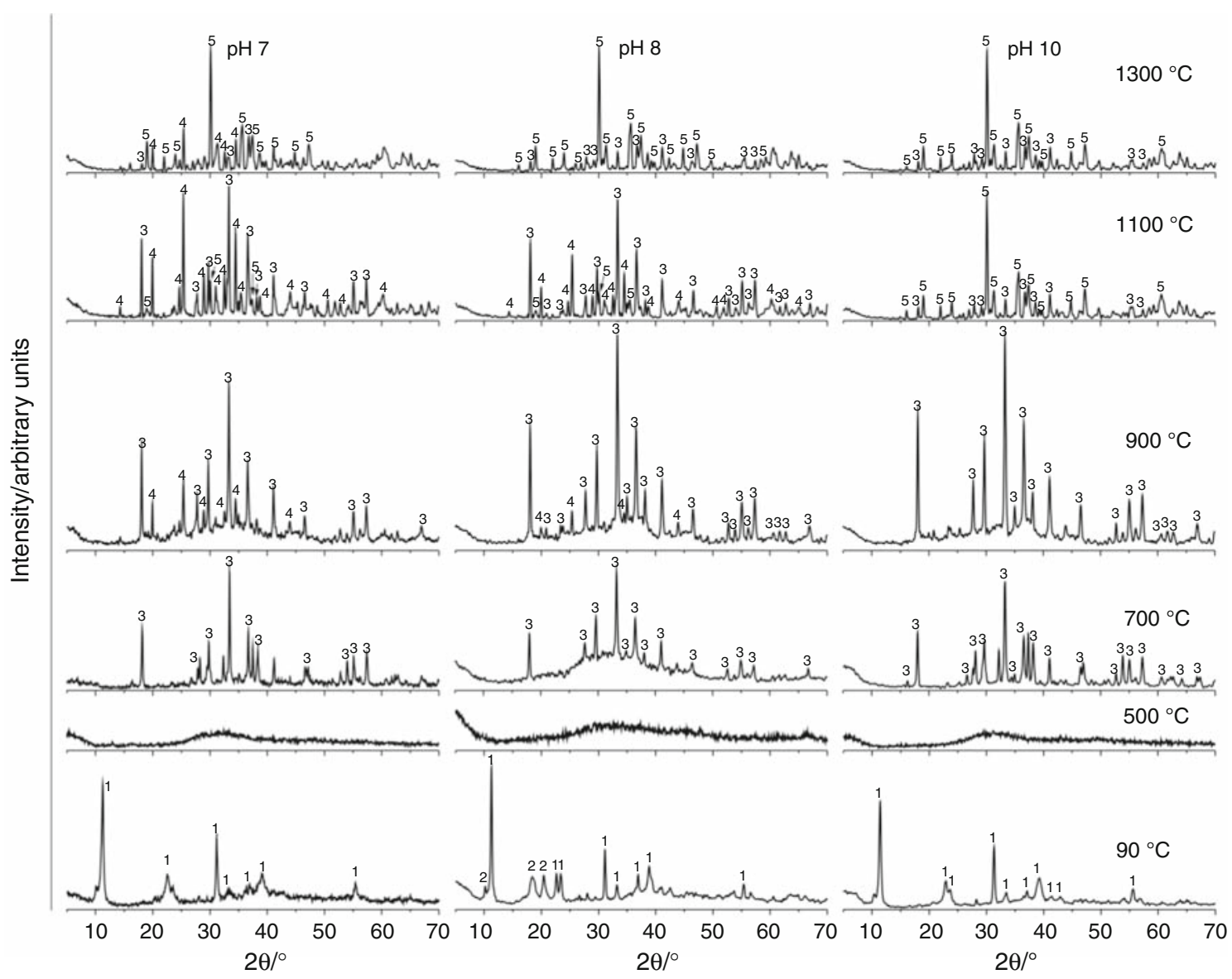

Fig. 1 XRD patterns of calcium aluminate precursors obtained at $\mathrm{pH} 7,8$ and 10, and samples obtained at different temperatures by thermal treatment of the corresponding precursor. $13 \mathrm{CaO} \cdot \mathrm{Al}_{2} \mathrm{O}_{3} \cdot \mathrm{CaCl}_{2} \cdot 10 \mathrm{H}_{2} \mathrm{O}$ (JCPDS 35-0105), $2 \mathrm{Ca}_{2} \mathrm{Al}_{2} \mathrm{O}_{5} \cdot 6 \mathrm{H}_{2} \mathrm{O}$ (JCPDS 12-0008), $3 \mathrm{C} 12 \mathrm{~A} 7$ (JCPDS 48-1882), 4 CA2 (JCPDS 72-0767), 5 CA (JCPDS 70-0134)

one and $\mathrm{Ca}_{2} \mathrm{Al}_{2} \mathrm{O}_{5} \cdot 6 \mathrm{H}_{2} \mathrm{O}$ (JCPDS 12-0008). Finally, some differences in crystallinity are observed between patterns and so for $\mathrm{pH} 8$ the reflections are better defined.

\section{Thermal treatment and XRD/SEM studies}

Precursors were heat treated at 150, 300, 500, 700, 900, 1100 and $1300{ }^{\circ} \mathrm{C}$ for $5 \mathrm{~h}$. At $150{ }^{\circ} \mathrm{C}$ (patterns not included), all samples exhibited XRD diffractograms similar to those corresponding to precursors, this means that at this temperature and from the crystallographic point of view, there are not any transformation. At $300{ }^{\circ} \mathrm{C}$ (patterns not included), all samples exhibited XRD diffractograms characteristic of amorphous materials. Thus, at this temperature, the crystallinity of the precursors is lost and the structural reorganization of elements starts. At $500{ }^{\circ} \mathrm{C}$, the patterns show that samples are still amorphous (Fig. 1).

The morphological aspect of the sample obtained at $\mathrm{pH}$ 8 and $500{ }^{\circ} \mathrm{C}$ can be seen at Fig. 2a, in which grains constituted by nanoparticles aggregates can be observed, this being characteristic of poor crystalline materials.
Figure $2 b$ shows a zone in which several crystallites start to growth, accordingly, this is the transition temperature between amorphous and crystalline calcium aluminate forms.

At $700{ }^{\circ} \mathrm{C}$, the diffraction maxima of $\mathrm{C} 12 \mathrm{~A} 7$ (JCPDS 48-1882) are observed for $\mathrm{pH} 8$ and 10, in this last sample the crystallinity of this phase is higher than in the first one. $\mathrm{C} 12 \mathrm{~A} 7$ is obtained as unique crystalline phase at a relatively low temperature and its formation is favoured in the case of the precursor obtained at the highest $\mathrm{pH}$ value. In the case of $\mathrm{pH} 7$ sample, the diffraction peaks fit much better to the phase JCPDS file 45-0568 which corresponds to $\mathrm{C} 12 \mathrm{~A} 7$ with partial substitution of oxygen atoms by chloride atoms $(1 \mathrm{O} / 2 \mathrm{Cl})$. Thus, the generated solid solution can be formulated as $\mathrm{Ca}_{12} \mathrm{Al}_{14} \mathrm{O}_{32} \mathrm{Cl}_{2}$.

At $900{ }^{\circ} \mathrm{C}$, the evolution of $\mathrm{C} 12 \mathrm{~A} 7$ to $\mathrm{CA} 2$ is observed for samples obtained at $\mathrm{pH} 7$ and 8 . Both the phases coexist at this temperature. This situation is not clearly identified

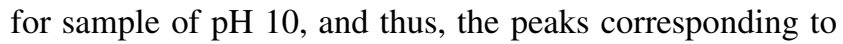
CA2 were not observed at this temperature. For this sample the transformation of $\mathrm{C} 12 \mathrm{~A} 7$ to $\mathrm{CA}$ starts to be produced 

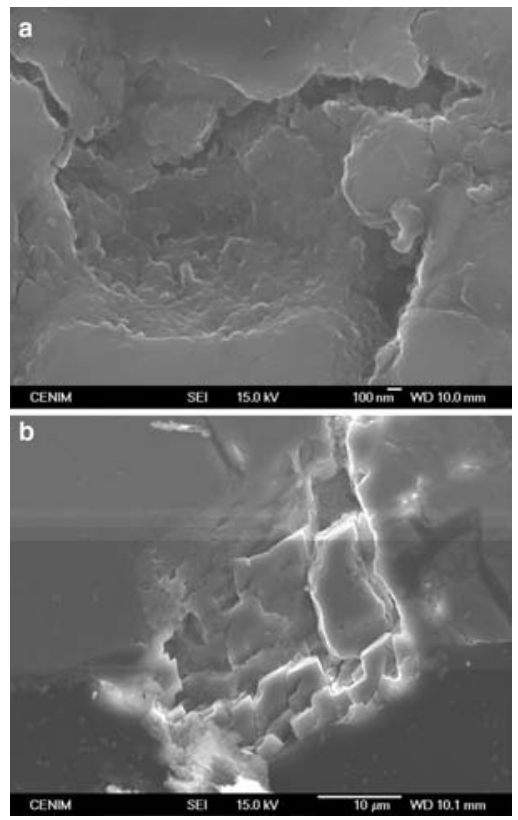

Fig. 2 SEM images of $\mathrm{pH} 8$ precursor heated at $500{ }^{\circ} \mathrm{C}$ a amorphous zone, b zone of crystalline growth

directly at $1100{ }^{\circ} \mathrm{C}$ (Fig. 1). For samples of $\mathrm{pH} 7$ and 8, CA reflections are also observed at this temperature along with reflections of CA2 and C12A7.

Figure 3a shows a crystal of C12A7 developed from the nanoparticles aggregates, obtained at $900{ }^{\circ} \mathrm{C}$ from $\mathrm{pH} 10$ sample. Figure $3 \mathrm{~b}$, corresponds to $\mathrm{pH} 7$ heated at $1100{ }^{\circ} \mathrm{C}$, two zones are clearly differenced at low magnification, $\mathrm{C} 2 \mathrm{~A}$ (zone 1) and C12A7 (zone 2). In Fig. 4, the
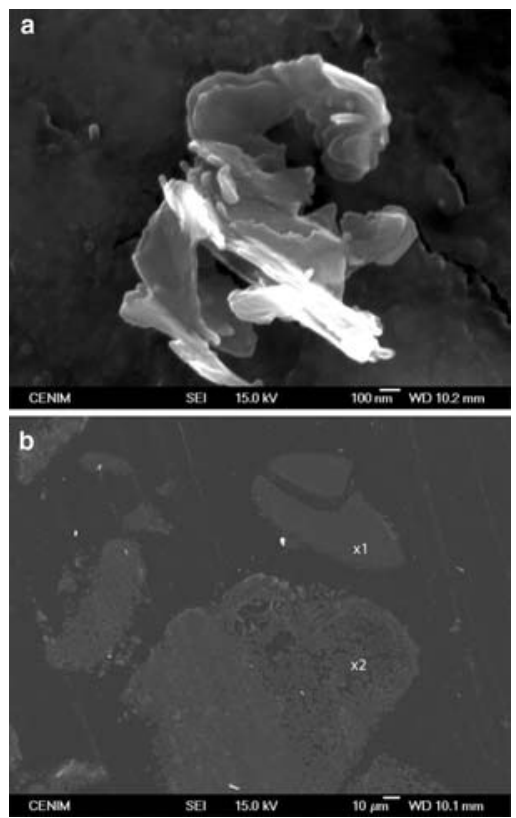

Fig. 3 SEM images a C12A7 crystal developed from nanoparticles aggregate obtained at $\mathrm{pH} 10$ and $900{ }^{\circ} \mathrm{C}, \mathbf{b} \mathrm{C} 2 \mathrm{~A}$ (zone 1) and $\mathrm{C} 12 \mathrm{~A} 7$ (zone 2), obtained at $\mathrm{pH} 7$ and $1100{ }^{\circ} \mathrm{C}$
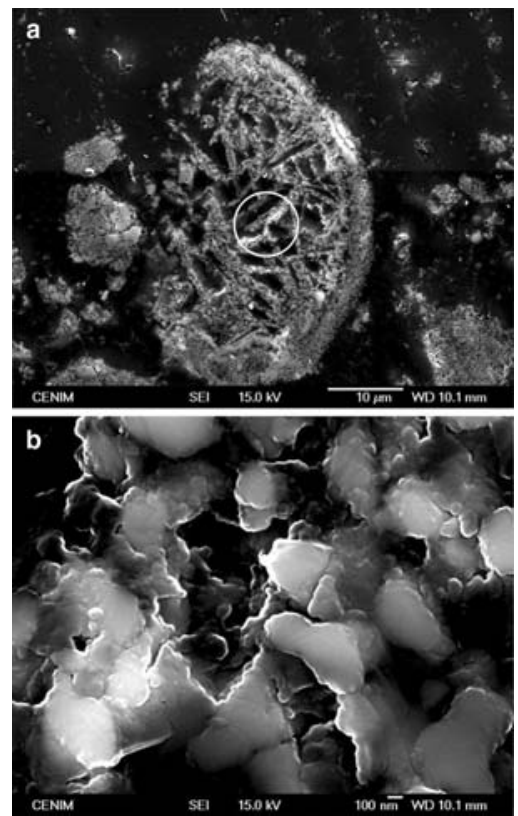

Fig. 4 SEM images of a microstructure of C12A7 b magnification of a dendrite zone

morphological aspect of C12A7 is shown, it is observed as a microstructure (Fig. 4a), formed by dendritical aggregate of nanospheres (Fig. 4b).

A specific surface area, $S_{\mathrm{BET}}$, of $175.3,150.6$ and $135.7 \mathrm{~m}^{2} \mathrm{~g}^{-1}$ was obtained for the precursors at $\mathrm{pH} 7,8$ and 10 , respectively. When samples are heated a drastic decreasing of $S_{\mathrm{BET}}$ was observed and so the specific surface area for the same samples heated at $1300{ }^{\circ} \mathrm{C}$ was $0.28,0.40$ and $0.29 \mathrm{~m}^{2} \mathrm{~g}^{-1}$ for samples of $\mathrm{pH} \mathrm{7,8}$ and 10 , respectively. This indicates a high sinterization of samples with temperature.

Table 1 Parameters determined by DTA and DTG (Fig. 5)

\begin{tabular}{|c|c|c|c|c|}
\hline Sample & $\begin{array}{l}\text { Temperature } \\
\text { range DTA } /{ }^{\circ} \mathrm{C}\end{array}$ & $\begin{array}{l}\text { DTA peak } \\
\text { area/ } \mu \mathrm{V} \mathrm{s} / \mathrm{mg}\end{array}$ & $\begin{array}{l}\text { Mass } \\
\text { variation } \\
\text { limit } /{ }^{\circ} \mathrm{C}\end{array}$ & $\begin{array}{l}\text { Mass } \\
\text { variation/ } \\
\%\end{array}$ \\
\hline \multirow[t]{5}{*}{ pH 7} & $74.7-184.7$ & 23.89 & $59.8-188.1$ & -3.58 \\
\hline & $184.7-407.8$ & 195.34 & $188.1-456.1$ & -23.05 \\
\hline & $661.5-742.7$ & 6.96 & $456.1-779.1$ & -4.29 \\
\hline & $817.1-896.6$ & 2.14 & 779.1-900 & -2.63 \\
\hline & $996.6-1079.4$ & 2.69 & & \\
\hline \multirow[t]{5}{*}{ pH 8} & $65.9-167.8$ & 12.54 & $75.8-176.3$ & -0.72 \\
\hline & $167.8-241.3$ & 3.39 & $176.3-534.9$ & -24.14 \\
\hline & $242.2-404.6$ & 131.48 & 538.7-751.6 & -3.16 \\
\hline & $712.3-770.7$ & 4.13 & $753.6-1275$ & -3.06 \\
\hline & $944.0-1054.0$ & 8.80 & & \\
\hline \multirow[t]{4}{*}{$\mathrm{pH} 10$} & $98.2-186.8$ & 26.33 & 71.7-190.0 & -4.57 \\
\hline & $186.8-396.1$ & 187.03 & $190.1-450.1$ & -20.65 \\
\hline & $800.4-888.1$ & 4.97 & 453.9-779.1 & -4.71 \\
\hline & $971.0-1092.9$ & 2.15 & $781.2-1285.5$ & -2.90 \\
\hline
\end{tabular}



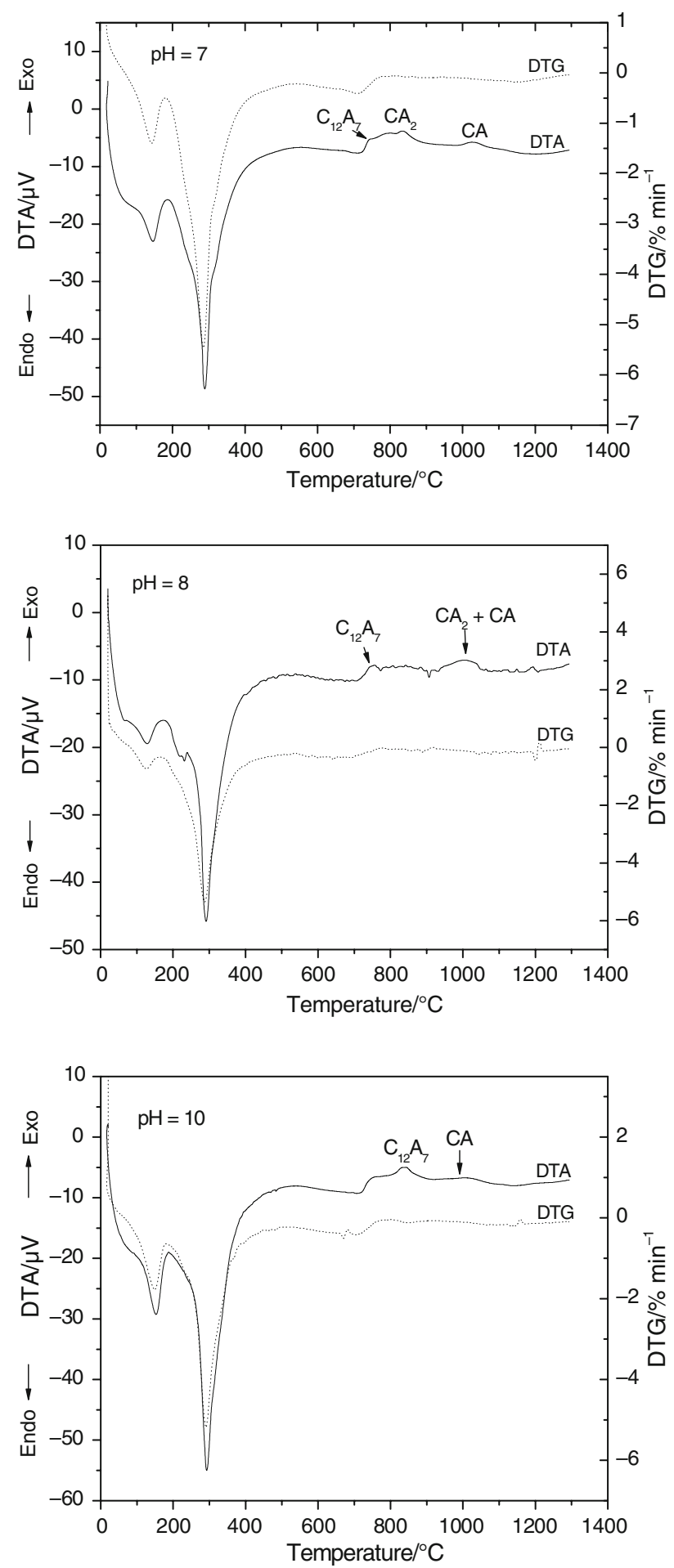

Fig. 5 DTA and DTG curves of samples obtained at $\mathrm{pH}$ 7, 8 and 10

TG/DTA analysis

The thermal behaviour of all the samples in non-isothermal conditions was studied between 25 and $1300{ }^{\circ} \mathrm{C}$. Table 1 collects the results of DTA and TG which includes the values of the temperature range and the peak area from

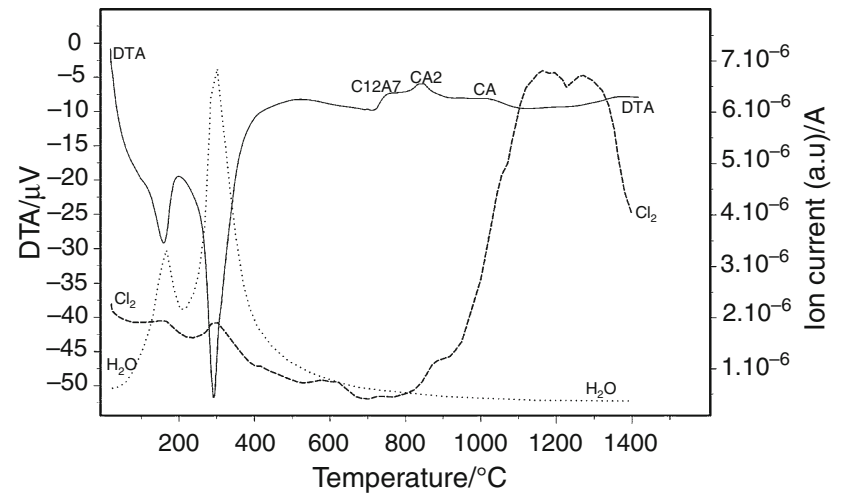

Fig. 6 DTA curve of sample obtained at $\mathrm{pH} 7$ and curves of emission of $\mathrm{Cl}_{2}$ and $\mathrm{H}_{2} \mathrm{O}$ obtained by mass spectrometry

DTA signal and the mass variation associated to the different thermal effects observed. The peak integration was performed using the software SETSOFT 2000 (vs.3.0.6) with a linear baseline from first to last point.

The DTA and the derivative TG (DTG) curves for all samples are shown in Fig. 5. Three zones can be clearly differenced in this figure. In the first zone, from room temperatures to 409,405 and $396{ }^{\circ} \mathrm{C}$ (for $\mathrm{pH} 7,8$ and 10, respectively), several endothermic effects are observed and they can be attributed to the loss of water, including the dehydration and dehydroxylation processes. Two effects are observed for sample obtained at $\mathrm{pH} 7$ and 10, but in the case of sample obtained at $\mathrm{pH} 8$, a third effect can be clearly distinguished. This agrees with the XRD results which indicate that this sample consists of two different phases of hydrated calcium aluminate. Mass variation around $25 \%$ for samples of $\mathrm{pH} 8$ and 10 and slightly higher, $26.6 \%$, for sample of $\mathrm{pH} 7$ was calculated from TG. The second zone stars at 662,712 and $800{ }^{\circ} \mathrm{C}$ for samples of $\mathrm{pH}$ 7, 8 and 10, respectively, and it attributed to the formation of $\mathrm{C} 12 \mathrm{~A} 7$ and $\mathrm{CA} 2$. The higher $\mathrm{pH}$ value, the higher starting temperature of aluminate formation. Finally, in the last zone, at temperature higher than $900{ }^{\circ} \mathrm{C}$ a lower than $1100{ }^{\circ} \mathrm{C}$, the CA formation occurs according to DTA. The formation of the different aluminate phases agrees to the XRD results and the bibliographic data [13, 14].

Mass spectrometry was used to confirm the presence of chlorine in the sample obtained at $\mathrm{pH} 7$. Figure 6 shows the DTA curve of sample obtained at $\mathrm{pH} 7$ along with the curves of emission of $\mathrm{Cl}$ and $\mathrm{H}_{2} \mathrm{O}$. The initial precursor in this case, and according to XRD was identified as the phase $3 \mathrm{CaO} \cdot \mathrm{Al}_{2} \mathrm{O}_{3} \cdot \mathrm{CaCl}_{2} \cdot 10 \mathrm{H}_{2} \mathrm{O}$. The elimination of water takes place principally at temperature lower than $400{ }^{\circ} \mathrm{C}$, in agreement with XRD and DTA results, but residual chlorine is eliminated mostly at temperature higher than $900{ }^{\circ} \mathrm{C}$. 


\section{Conclusions}

A hazardous waste from tertiary aluminium industry can be used as a raw material for the synthesis of calcium aluminate. An amorphous precursor was obtained by a hydrothermal method at different values of $\mathrm{pH}$. The transformation of the precursor in a crystalline aluminate was followed by TG/DTA up to $1300{ }^{\circ} \mathrm{C}$. All the techniques used to characterize the samples give similar or complementary results, so as conclusion the calcium aluminates precipitated from $700^{\circ}$. The first aluminate formed is $\mathrm{C} 12 \mathrm{~A} 7$. This aluminate has a transition to $\mathrm{CA} 2$ at $838_{-}$ $848{ }^{\circ} \mathrm{C}$ and then is transformed to CA at $1000-1034{ }^{\circ} \mathrm{C}$, which coexists with the previous one. The phase $\mathrm{C} 12 \mathrm{~A} 7$ was obtained as unique crystalline phase, at $900{ }^{\circ} \mathrm{C}$, in the case of precursor obtained at $\mathrm{pH} 10$.

Acknowledgements The authors thank the MEC for financing project CTM2005-01964 and the company Recuperaciones y Reciclajes Roman S.L. (Fuenlabrada, Madrid, Spain) for supplying the waste and Dr. M. I. Martín for the FRX analysis and Dr. I. Padilla for the technical assistance. Laura Delgado-Gonzalo is grateful to the CSIC (Spanish National Research Council) for an I3P contract.

\section{References}

1. Gaki A, Chrysafi R, Kakali G. Chemical synthesis of hydraulic calcium aluminate compounds using the Pechini technique. J Eur Ceram Soc. 2007;27:1781-4.

2. Hidalgo A, Garcia JL, Alonso MC, Fernández L, Andrade C. Microstructure development in mixes of calcium aluminate cement with silica fume or fly ash. J Therm Anal Calorim. 2009;96: $335-45$.
3. Raab B, Pöllmann H. 9th Conference of applied mineralogy, Brisbane, Australia 2008. p. 245-53.

4. Gülgün MA, Popoola OO, Kriven WM. Chemical synthesis and characterization of calcium aluminate powders. J Am Ceram Soc. 1994;77:531-9.

5. Tas AC. Chemical preparation of the binary compounds in the calcia-alumina system by self-propagating combustions synthesis. J Am Ceram Soc. 1998;81:2853-63.

6. Gonzalo-Delgado L. Obtención y caracterización de bohemita a partir de un residuo peligroso de la industria del aluminio. Master Project. Digital CSIC Free Data Base 2008. http://hdl.handle. net/10261/6195.

7. Directive 2008/98/EC of the European parliament and of the council, on waste (19 nov. 2008).

8. López FA, Peña MC, López-Delgado A. Hydrolysis and heat treatment of aluminium dust. J Air Waste Manag Assoc. 2001;51:903-12.

9. López-Delgado A, Tayibi H, López FA. Treatments of aluminium dust: a hazardous residue from secondary aluminium industry. New York: Nova Publisher; 2007. p. 1-52. ISBN 1-60021-452-5.

10. Shinzato MC, Hypolito R. Solid waste from aluminium recycling process: characterization and reuse of its economically valuable constituents. Waste Manag. 2005;25:37-46.

11. López-Delgado A, Tayibi H, Alguacil FJ, López FA. A hazardous waste from secondary aluminium metallurgy as a new raw material for calcium aluminate glasses. J. Hazardous Mater. 2009;A65:180-6.

12. López-Delgado A, Jiménez JA, Alguacil FJ, López FA. XLVIII Congreso Anual de la Sociedad Española de Cerámica y Vidrio. Oviedo, Spain, 2008. http://hdl.handle.net/10261/8191.

13. Ubbriaco P, Traini A, Manigrassi D. Characterization of FDR fly ash and brick/lime mixtures. J Therm Anal Calorim. 2008; 92(1):301-5.

14. Douy A, Gervais M. Crystallization of amorphous precursors in the calcia-alumina system: a differential scanning calorimetry study. J Am Ceram Soc. 2000;83:70-6. 